\title{
The fragility of the hemodynamic balance in the elderly: possible influences on the inner ear
}

\author{
A Pirodda ${ }^{1 *}$, MC Raimondi ${ }^{2}$ \\ From de Senectute: Age and Health Forum \\ Catanzaro, Italy. 5-7 December 2009
}

The possible occurrence of labyrinthine disorders linked to hemodynamic imbalances has been widely outlined [1-4] and well demonstrated by clinical observations concerning both young and healthy people [4] and subjects suffering from cardiovascular affections as hypertension - the prevalence of tinnitus was studied in patients under antihypertensive [5] - or heart failure of variable severity [6]. In all cases, a possible influence of a sharp decrease in the values of blood pressure followed by an abnormal vasomotor reaction was postulated to have some role in the genesis of the disorder, mostly when considering that blood supply of the inner ear is of terminal type. In the elderly, the problem is even more complicated by the frequent presence of isolated systolic hypertension, which is characterized by the lowered compliance of the vascular tree, presenting with an increase of the arterial stiffness and reported to be due both to age-related loss of distensibilty in the major central arteries and to endothelial dysfunction [7]: this increases, in general terms, the risk of transient hypoperfusion to an organ with a terminal circulation as the labyrinth and represents a crucial factor to deal with when treating hypertension in elderly. Moreover, the possibility of the so-called "hypertension-hypotension syndrome" [8], i.e. the coexistence of supine hypertension and orthostatic hypotension as a result of dysautonomia [7] represents a further complication in this sense. Hence the necessity of choosing, when possible, an antihypertensive therapy able to protect the endothe-

\section{Author details}

Department of Specialist Surgical and Anesthesiological Sciences, University of Bologna, Italy. ${ }^{2}$ Posgraduate School of Audiology and Phoniatrics, University of Bologna, Italy.

Published: 27 August 2010

\section{References}

1. Pirodda A, Saggese D, Ferri GG, Giausa A, Grippo MC, Gaddi A: The role of hypotension in the pathogenesis of sudden hearing loss. Audiology 1997, 36:98-108.

2. Pirodda A, Ferri GG, Modugno GC, Borghi C: Systemic hypotension and the development of acute sensorineural hearing loss in young healthy subjects. Arch Otolaryngol Head Neck Surg 2001, 127:1049-52.

3. Pirodda A, Ferri GG, Montana T, Riggio R, Innocenti G, Di Nino G: Hypotension as an isolated factor may not be sufficient to provole hearing impairment. J Laryngol Otol 2004, 118:941-5.

4. Degli Esposti D, Raimondi MC, Dormi A, Cosentino ER, Bacchelli S, Brandolini C, Modugno GC, Borghi C, Pirodda A: Hemodynamic profile of young subjects with transient nitus. Audiol Med.

5. Borghi C, Brandolini C, Prandin MG, Dormi A, Modugno GC, Pirodda A: Prevalence of tinnitus in patients with hypertension and the impact of different antihypertensive drugs on the incidence of tinnitus: a prospective, single-blind, observational study. Curr Ther Res 2005, 66:420-32.

6. Degli Esposti D, Cosentino ER, Santi F, De Sanctis D, Dormi A, Baccelli S, et al: Tinnitus and blood pressare values in heart failure patients. Proceedings of the 17th European Meeting on hypertension, Milan 2007, S171.

7. Stokes GS: Management of hypertension in the elderly patient. Clin Interv Aging 2009, 4:379-89.

8. Naschitz JW, Slobodin G, Elias N, Rosner I: The patient with supine hypertension and orthostatic hypotension: a clinical dilemma. Postgrad Med J 2006, 82:246-53.

doi:10.1186/1471-2318-10-S1-L84

Cite this article as: Pirodda and Raimondi: The fragility of the hemodynamic balance in the elderly: possible influences on the inner ear. BMC Geriatrics 2010 10(Suppl 1):L84. 